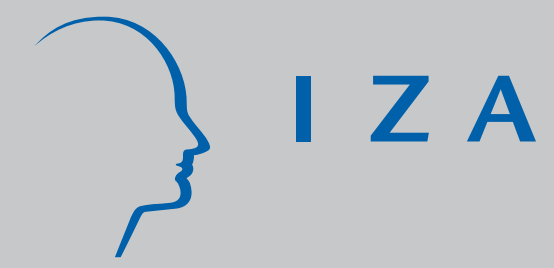

IZA DP No. 1320

Pre-Marital Fertility and

Labour Market Opportunities:

Evidence from the 1970 British Cohort Study

Emilia Del Bono

September 2004 


\title{
Pre-Marital Fertility and Labour Market Opportunities: Evidence from the 1970 British Cohort Study
}

\author{
Emilia Del Bono \\ Queen's College, University of Oxford, \\ University of California, Berkeley and IZA Bonn
}

Discussion Paper No. 1320
September 2004

IZA
P.O. Box 7240
53072 Bonn
Germany

Phone: +49-228-3894-0

Fax: +49-228-3894-180

Email: iza@iza.org

\begin{abstract}
Any opinions expressed here are those of the author(s) and not those of the institute. Research disseminated by IZA may include views on policy, but the institute itself takes no institutional policy positions.

The Institute for the Study of Labor (IZA) in Bonn is a local and virtual international research center and a place of communication between science, politics and business. IZA is an independent nonprofit company supported by Deutsche Post World Net. The center is associated with the University of Bonn and offers a stimulating research environment through its research networks, research support, and visitors and doctoral programs. IZA engages in (i) original and internationally competitive research in all fields of labor economics, (ii) development of policy concepts, and (iii) dissemination of research results and concepts to the interested public.
\end{abstract}

IZA Discussion Papers often represent preliminary work and are circulated to encourage discussion. Citation of such a paper should account for its provisional character. A revised version may be available directly from the author. 


\section{ABSTRACT \\ Pre-Marital Fertility and Labour Market Opportunities: Evidence from the 1970 British Cohort Study*}

This paper investigates the effect of earnings and employment opportunities on pre-marital fertility. Using data from a sample of British women born in 1970, we estimate an independent competing risks hazard model of fertility and cohabitation decisions. Our results show that individual earnings opportunities are negatively related to pre-marital fertility but do not affect union formation. Local male unemployment, on the contrary, is a positive determinant of single motherhood and a negative factor in cohabitation decisions. The latter result is consistent with the Wilson hypothesis as it shows the existence of a direct effect of male joblessness on co-residential relationships.

JEL Classification: J13, J12, C41

Keywords: fertility, marriage, competing risks hazard models

Emilia Del Bono

Centre for Labor Economics

University of California, Berkeley

2521 Channing Way \#5555

Berkeley, CA 94720-5555

USA

Email: emilia.delbono@economics.oxford.ac.uk

\footnotetext{
* The data from the 1970 British Cohort Study has been obtained through the UK Data Archive. Peter Shepherd and Brian Dodgeon of the Centre for Longitudinal Studies (CLS), Institute of Education, London, helped with some of the derived variables used in this study. Chris Hunt of the Office for National Statistics (ONS), London, provided county level variables derived from the New Earnings Survey. I would also like to thank Francesca Bettio, John Ermisch, Mary Gregory, Steve Nickell, Margaret Stevens and Daniela Vuri for very helpful comments. An earlier version of this work was presented at seminars held at the University of Oxford, at the Royal Holloway, University of London, and at the 2004 European Society for Population Economics Conference in Bergen. All mistakes are my full responsibility.
} 


\section{Introduction}

In recent decades, across most European countries as well as in the United States, there has been a considerable increase in the proportion of births occurring outside marriage. In particular in the UK, the percentage of non-marital births has risen from $9 \%$ to $40 \%$ between 1975 and 2001, and in the space of one generation the numbers marrying have halved, the numbers divorcing have trebled, and about three in four women now cohabit before getting married. All these factors have contributed to the separation of marriage and parenthood, so that not only is there an increasing tendency to cohabit, but more women in cohabiting relationships have children (Ermisch and Francesconi, 2000; Ermisch, 2001).

What is happening to cohabitation in Britain is still a very difficult question to answer. The speed with which this phenomenon took place and spread across different cohorts and social classes makes it particularly difficult to study. ${ }^{1}$ Moreover, one has to be cautious about making comparisons with marriage, as marriage has changed too and, although it remains an institution, it is now much more open to negotiation than it ever was in the past (Lewis, 2001). Therefore, from a social policy point of view, it is not clear how the system should respond to an increase in cohabitation.

On the other hand, it seems much more obvious to focus on children born outside any type of co-residential partnership, in particular because in this respect Britain is an exception. Kiernan (2001) shows that, although across Europe the percentage of children born outside any partnership has fallen over recent cohorts, in the UK this trend has been different and the percentage of first births before any partnership has more than doubled, rising from $6 \%$ in the 1980 s to $15 \%$ in the 1990 s.

Since non-marital childbearing reduces subsequent union formation (Upchurch et al., 2001), the context in which a child is born has strong implications for the number of years that child will spend with one parent. Much public apprehension about the growth of out-of-wedlock childbearing stems from the fact that in these circumstances the economic contribution of fathers to their children falls to an inefficiently low level and this increases the prevalence of child poverty (Willis, 2000). This is a serious concern and explains why we are mainly interested in the determinants of single motherhood and, in particular, why we intend to focus our analysis on the influence of labour market opportunities on pre-marital childbearing. ${ }^{2}$

Using data from a single cohort of British women born in 1970, we estimate the effect of various socioeconomic variables on the conditional probability of a transition into pre-marital fertility or into a first cohabiting relationship by means of an independent competing risk hazard model. We find that higher individual earning potential is significantly and negatively related to pre-marital fertility but is not an important determinant of partnership decisions. By contrast, poorer employment opportunities have a positive impact on extra-marital childbearing and a negative influence on the formation of coresidential relationships.

This paper is divided as follows. In the next section we offer a brief review of the literature on the determinants of pre-marital fertility, mainly focusing on studies which

\footnotetext{
${ }^{1}$ See Kiernan et al. (1998) for an extensive study of lone motherhood in Britain from an historical perspective.

${ }^{2}$ In what follows we use terms such as non-marital, pre-marital, extra-marital, out-of-wedlock fertility indifferently. In our analysis, however, we look only at conceptions prior to any co-residential partnership.
} 
analyse the impact of labour market opportunities. Our data is described in section 3 , where we also provide details of the sample selection process and some descriptive statistics for the main explanatory variables. The empirical model and the methodology used in this study are presented in section 4 . Section 5 presents our results, first with respect to pre-marital fertility and then to cohabitation decisions. Section 6 concludes.

\section{Previous studies}

Two different types of studies suggest that economic factors may contribute to women having children prior to a cohabiting relationship. One group emphasises the role of the welfare system in making single motherhood more economically attractive (Murray, 1984) and calls for programmes intended to support children in single-headed families to be scaled down. The other group argues for state intervention and proposes the 'male joblessness' hypothesis as the primary economic determinant of out-of-wedlock births.

Welfare benefits seem an obvious place to begin the search for the determinants of nonmarital childbearing. Most of the research into this causal linkage has taken place in the United States, where it is possible to exploit intertemporal and cross-sectional variation in welfare programmes such as the Aid to Families with Dependent Children (AFDC).

However, the basic statistics do not provide much support for the hypothesis that welfare leads to single motherhood: the inflation-adjusted value of AFDC and related programmes consistently declined from the early 1970s to the late 1980s, when female headship had in fact been increasing. Moreover, even if results from cross-sectional studies reveal a positive impact of welfare on non-marital fertility, there is still strong disagreement about the magnitude of this effect (Moffitt, 1998).

Wilson and Neckerman (1986) and Wilson (1987) propose another explanation for the increase in non-marital fertility that has received a great deal of attention. Their work gives the role of male employment and labour force participation a central position in explanations of the family decisions of women. They claim that the decline in marriage rates among blacks, particularly among poor inner-city blacks, is due primarily to declining black male employment levels, resulting in a diminishing pool of acceptable marriage partners for black women. To support this claim, Wilson constructs a 'male marriageable pool index', given by the number of employed men per woman of the same age and race. He shows that this index declined from the late 1960s through the early 1980s and that the decline coincided with a reduction in marriage rates, therefore suggesting that male joblessness is positively related to female headship rates.

The work of Julius Wilson has been highly influential in the economic literature on non-marital fertility. Recent theoretical models combine traditional economic theories of fertility and marriage (Becker 1960, 1973, 1974) to generate models of non-marital childbearing compatible with the Wilson hypothesis. So, for example, Willis (1999) shows that, under specific circumstances, out-of-wedlock fertility is the outcome of the optimising behaviour of men and women drawn from the lower part of the income distribution. A similar result is found in Burdett and Ermisch (2002), who propose a theory of outof-wedlock fertility directly derived from search and matching models of labour market behaviour.

However, the vast bulk of research into the Wilson's hypothesis has been mainly empirical in nature. According to Ellwood and Crane (1990), for example, some of the most interesting and powerful criticism of the Wilson hypothesis comes from examining 
broad 'facts'. In particular, one would expect that marriage rates should have fallen far more for those doing poorly in the labour market than for those doing well, but Lerman (1989) shows that the declines have been almost as great for better-educated men as for the less well educated. Moreover, one should observe an increase in marriage rates for the scarce marriageable men left on the market, while it appears that high-earning blacks are still much less likely than whites to be married. More recent empirical tests of the Wilson hypothesis find that a decline in the 'male marriageable pool index' can explain only a tiny fraction (between 3 to $4 \%$ ) of the decline in black marriage rates in the 1970s (Wood, 1995).

Other studies consider the Wilson hypothesis as part of a broader framework, and investigate the overall effect of labour market opportunities on out-of-wedlock births. These include the seminal work of Olsen and Farkas (1990) for the United States and of Ermisch (2002) for Britain. In both these papers the authors estimate the effect of local employment opportunities on individual relationship and childbearing decisions using temporal and spatial variation in measures of local employment (or unemployment) rates.

As well as recognizing that local unemployment rates may affect male job opportunities and therefore women's marriage rates, these studies point to the existence of another reason why local labour market opportunities are correlated to pre-marital childbearing: the woman's opportunity-cost of having children. Since male and female job opportunities are typically strongly correlated across local areas and over time, any increase in male employment rates will cause an increase in the marriage rates but also a decrease in fertility via the female opportunity-cost effect. The two effects work in the same direction and non-marital fertility decreases both because the period at risk of a non-marital birth is reduced and because the demand for children diminishes.

In order to evaluate the relative strength of the male joblessness effect and the female opportunity-cost effect, Olsen and Farkas (1990) estimate a hazard rate model for entry into cohabitation and then estimate a fixed-effects hazard model for illegitimate fertility after removing individuals who have already entered a cohabiting relationship. The first regression is explicitly related to the Wilson hypothesis and they find that local male employment rates are positively and significantly related to cohabitation/marriage decisions, although the effect is not large. Assuming that cohabitation is exogenous to childbearing, only women who have not as yet married or started a cohabiting relationship are included in the second regression. Here the results indicate a very large and negative effect of employment opportunities on non-marital fertility. The difference between the magnitude of the effects of employment rates in the fertility and partnership equations leads them to conclude that, although the mechanism hypothesised by Wilson is important, the male joblessness effect is less important than the female opportunity-cost effect.

A similar conclusion is found in Ermisch (2002), who uses data from the first ten years of the British Household Panel Study and male unemployment rates matched on about 300 travel-to-work-areas to determine the impact of employment opportunities in the local area on the probability that a childless never-married woman has a birth outside marriage. The methodology is similar to the one adopted by Olsen and Farkas (1990), as partnership and childbearing decisions are assumed to be independent events. Analysing the effect of local unemployment rates on the hazard of a birth outside marriage and on the hazard of marriage, Ermisch (2002) finds evidence that local employment opportunities affect pre-marital fertility but do not directly influence partnership formation.

Our work is related to this line of enquiry. In this paper, we analyse the effect of 
labour market opportunities on pre-marital fertility using monthly observations on the relationships and fertility histories of a sample of women from the 1970 British Cohort Study. We estimate an independent competing risks hazard model of fertility and cohabitation decisions of women aged 17 to 30 and analyse the effect of time-varying county-level economic variables on the probability that a single and childless woman has a conception before entering a cohabiting relationship. Using time-invariant information on the area of residence we also identify the effect of individual potential earnings on the fertility and cohabitation hazards.

With respect to the previous literature, we are able to achieve greater control over heterogeneity in individual characteristics, as we observe a vast array of variables related to the socioeconomic features of our subjects and their family of origin. In addition, by introducing measures of individual potential wages we can explore to what extent predetermined characteristics of the subject and her family have a direct effect on a woman's fertility and partnership history or act mainly indirectly, by influencing her earnings opportunities.

Our main findings show that measures of female earnings opportunities are significantly and negatively related to pre-marital fertility and negatively but not significantly related to women's cohabitation decisions. On the other hand, area-specific male unemployment rates are found to be positively related to out-of-wedlock births and negatively related to union formation. Both these effects are statistically significant and we interpret the latter result as evidence in favour of the Wilson hypothesis.

\section{The data}

The main source of data for this analysis is the 1999/2000 follow-up of the 1970 British Cohort Study (BCS70), a continuing longitudinal survey which takes as its subjects all those living in Great Britain who were born between 5th and 11th April 1970 (Butler et al., 1997; Despotidou and Shepherd, 1998; Bynner et al., 2000). The last wave photographs the individuals at the age of 30 and covers their transitions to adult life, including: leaving full-time education, entering the labour market, setting up independent homes, forming partnerships and becoming parents. It consists of 11,261 individuals, 5,790 of whom are women and a retrospective questionnaire which covers the period between April 1986 and the 1999/2000 interview date.

In selecting our sample of women we first looked at the information on fertility and relationship histories. Missing values and various inconsistencies across these variables were found and this reduced the sample to 5,022 valid cases. We set the initial date of observation at age 16, precisely at October 1986, when the subjects have completed their period of compulsory schooling. Women who drop out of school before age 16 or for whom we do not have the date of completion of full-time education (119 observations) are not considered. Since our time-varying regressors are lagged one year with respect to birth and cohabitation events, 144 subjects who have a first pregnancy or enter the first cohabiting relationship before age 17 are also excluded. Further checks on personal and family background characteristics collected from different surveys reduced the number of valid cases to 4,120 women. We then matched this information with aggregate series for wages and skill levels derived from the New Earnings Survey. Because of small cell size, 
complete series of these variables were not available for some of the counties. ${ }^{3}$ This means that the total number of individuals in our final sample is 4,036 , about $70 \%$ of all the women originally included in the 1999/2000 sweep of the BCS70.

Our dependent variable is represented by an exit into one of two mutually exclusive states: a 'first child' or a 'first cohabiting relationship'. Since we have accurate monthly information on the date of birth of the child and on the date of beginning and end of each cohabiting relationship, we analyse the very first event which took place. Women who were not in a cohabiting relationship up to nine months before the birth of their first child are considered single mothers. This definition includes women who remain single at the time of the birth of the child and those who enter a cohabiting relationship after conceiving their first baby. All the other women either experience first an entry into a cohabiting relationship or never exit the state of single and childless before age 30 .

Almost $52 \%$ women in our sample become mothers by the end of the observation period, which implies that the percentage of childless women is about $48 \%$ by age $30 .{ }^{4}$ The mean age at the birth of the first child regardless of cohabitation status is about 25.5 years and the median is 26 . About $13.4 \%$ of women in our sample become single mothers (see Table 1), while $76.4 \%$ experience the first transition directly into a formal or informal union. ${ }^{5}$ The remaining $10.2 \%$ of the sample does not experience either of the two events by age 30 . These numbers imply that one in four first births (about 26\%) are classified as births outside a cohabiting relationship and that the mean age at the birth of the first child is slightly above 21 years for single mothers. ${ }^{6,7}$

Figure 1 shows the smoothed hazard functions for exits into pre-marital fertility and cohabiting relationships. The data reveals almost no duration dependence in the "first birth' hazard. By contrast, as we can see in Panel A, the 'first cohabiting relationship' hazard function clearly exhibits positive and then negative duration dependence, achieving its maximum around age 26. Looking only at the 'first child' hazard and changing the

\footnotetext{
${ }^{3}$ Aggregate series for hourly wage rates and skill levels by county and gender were provided by the ONS on specific request. For some of the smallest counties complete series of these variables were not available, as the number of observations per cell was too small to comply with the New Earnings Survey release criteria.

${ }^{4}$ The percentage of women childless by age 30 in our sample is slightly higher than that recorded for the entire BCS70 survey, which is about $46 \%$. This difference is perhaps due to the fact that we excluded from the sample women with inconsistent family and cohabitation information and these individuals are predominantly women with children. It should also be noted that the percentages of childless women by age 30 in the whole BCS70 and in our sample are both substantially higher than what is recorded by the Office for National Statistics in the series Birth Statistics: Births and Patterns of Family Building England and Wales (FM1), which indicates that about $40 \%$ of women born in 1970 were still childless by age 30 (see year 2000).

${ }^{5}$ We include all marriage and cohabitation spells, irrespective of their duration. As a robustness check, we conducted our analysis considering only non-censored partnership spells lasting more than twelve months, but this did not have any significant impact on our results.

${ }^{6}$ Using data from the National Child Development Study, which represents a cohort of British women born in 1958, Berrington and Diamond (2000) report that about $17 \%$ of conceptions occurred before the formation of a co-residential partnership. Thus, the percentage of children conceived before a cohabiting relationship seems to have increased over time.

${ }^{7}$ Adopting a narrower definition of single mothers and considering only women whose first baby is born before any cohabiting relationship modifies some of the above statistics. According to our calculations, in this second scenario we would observe around $8.6 \%$ births to single women and $81 \%$ exits into a cohabiting relationship, while the number of babies born outside a cohabiting union would account for almost $17 \%$ of all first births. In this case the mean age at the birth of the first child would be just below 21 years for single mothers. Using this definition of single mothers did not significantly affect our results.
} 
scale of the vertical axis, in Panel B we see that this function peaks around age 20 (when the hazard rate reaches an approximate value of $0.23 \%$ ) and decreases afterwards, moving around an average value of $0.16 \%$ until the end of the observation period. This implies that although the risk of a pre-marital conception is higher at a younger age, single motherhood is not exclusively associated with teenage women and remains a nonnegligible phenomenon later on in life as well.

Table 1 reports the mean and the standard deviation of the explanatory variables for the entire sample and, separately, for the subsample of women who experience a pre-marital birth and those whose first exit is into a cohabiting relationship. We look first at the individual's time-invariant characteristics, such as the hourly wage rate and employment rate at age 30, schooling, ability scores, behavioural scores, and ethnic group. Then we look at the family background of the subject, focusing on the fertility and marital history of the woman's mother, the education of both parents, household income and composition, other indicators of family status such as the tenure of accommodation, the social class of the father and mother, and the interest of the mother in the subject's educational achievements. Next, we consider time-varying county-level variables in order to describe the characteristics of the local labour market in which the subjects live from age 16 to age $29 .^{8}$

As we can see, women who have a pre-marital birth are characterized by a lower loghourly wage at age 30 and a much lower employment rate than that of all women in the sample or that of women who exit into a first cohabiting union. The logarithm of the hourly wage rate for single mothers indicates that this is almost $£ 2$ lower than the average for the whole sample, while we see that only less than one in two women in the 'first child' subsample are employed at the date of the last interview as compared to $73.3 \%$ in the other subsample.

Also very significant is the difference in the level of schooling, summarized here by a dummy variable with value one if the subject left full-time education at age 16 and zero if she continued. Correspondingly, the distribution of ability and behavioural test scores changes quite dramatically across the two subsamples. ${ }^{9}$

Perhaps surprisingly, there are no statistically significant differences by ethnic group. This might be due to the very small number of women from different ethnic minorities included in the BCS70. Further investigation on other related variables, such as the country of birth of the mother of the subject, did not lead to a different picture, either in the descriptives or in the final analysis. Other characteristics of the subject's mother, such as her age and marital status at the birth of her first child (not at the birth of the cohort member) are instead important factors which are often thought to influence a woman's risk of having a pre-marital birth and our data show how significant the variation is across the two subsamples.

All the variables related to the mother's and father's education and social class and their combined income as measured at 1980 reveal that women who become single mothers come from a more disadvantaged family background. In particular, differences in the type

\footnotetext{
${ }^{8}$ All the time-varying county-level variables are lagged one year with respect to the age of the subject.

${ }^{9}$ Ability is measured by the first principal component derived from a set of tests (Friendly Maths Test, Edinburgh Reading Test, and British Ability Scales) performed by the subject at age 10. The behavioural score is calculated using principal component analysis to derive a unitary measure of antisocial behaviour described by a set of 53 questions asked to the child's class teacher. In both cases, principal component analysis was carried out on the entire sample of subjects participating in the survey at age 10 (Dearden, 1998) and the resulting variable has been standardised in order to have mean zero and unit variance.
} 
of tenure of accommodation are very marked. Women who become single parents are more than twice as likely to live in council housing than women who enter into a cohabiting relationship. A test of the difference between subsamples reveals a chi-squared statistics of 165.93 (p-value 0.0000), showing a difference in the distribution of the two groups according to this variable which is almost as significant as that observed with respect to schooling (chi-squared 181.53).

One of the most important variables in our analysis is the geographical location of the cohort members, which is used to identify the influence of labour market characteristics. Information on standard statistical regions is available from all the different BCS70 surveys, but details of the place of residence at the sub-regional level is more difficult to gather. The 1999/2000 survey contains details of the housing history of each individual and her geographical mobility from age 16 to age 30, but most area variables remain strictly protected for confidentiality reasons. The only source of information at the subregional level that is publicly available is given by the Local Educational Authorities at age 10 and age 16 .

Since the 16-year follow-up is affected by severe attrition problems, we use information on area of residence at age $10 .{ }^{10}$ We map about 120 Local Educational Authorities into 66 English and Welsh counties and Scottish L.A. regions. Then we match individuals with time series of county-level variables according to their area of residence at age 10. Given changes in the geographical structure of English and Welsh counties and of Scottish L.A. regions and given the small dimension of some of these units, only 57 geographical areas are used in the final analysis.

The county-level variables of interest are mainly collected from official statistics and cover the period between January 1986 and December 1999. The unemployment rate is given by the ratio of male claimants to the number of working age men living in a certain area. Monthly information on claimant counts by age and gender was obtained by the official labour market statistics published through NOMIS, while mid-year population estimates for each county were provided by the Office for National Statistics for England and Wales (ONS) and the General Register Office for Scotland (GRO-Scotland). We considered a 9-month moving average of this series in order to smooth out seasonal variations.

Finally, yearly observations for wages and skills composition of female employees are derived from the New Earnings Survey, a large sample survey of UK employees. The data cover hourly and weekly earnings plus detailed information on hours, overtime, age, occupation, industry and geographical area of employment. We use the male/female hourly wage ratio and the composition of female employment by skills (taken as a proxy of educational qualifications of the female population) derived by grouping the major occupational groups as proposed in Gregory et al. (2001). ${ }^{11}$ All these variables are derived for women aged 16-59 and men aged 16-64 and refer to full-timers only.

\footnotetext{
${ }^{10}$ We therefore assume that at 16 individuals reside in the same county they lived in at age 10 and, more generally, that there is very little mobility of people across counties over time. Unfortunately, given our data limitations, we cannot adequately control for this assumption. However, census data indicate that in 1991 the number of people who moved across counties in the past year was only $2.3 \%$ for the total population and $1.5 \%$ for people aged 10-15. It seems therefore unlikely that this constitutes a serious problem in our analysis.

${ }^{11}$ High skills are represented by SOC groups 1-3 (managers, professionals, and associate professionals), intermediate skills comprise SOC groups 4-7 (clerical and secretarial, craft, personal services, and sales), and low skills are indicated by SOC groups 8-9 (machine operatives, and others).
} 


\section{The empirical model}

In this study we intend to measure the effect of employment and earnings opportunities on pre-marital fertility and co-residential relationships. Individual measures of employment and earnings are potentially endogenous because they can be influenced by unobservable characteristics of the subject which may also affect fertility and cohabitation decisions. Our approach to the identification of the true impact of employment and earnings opportunities on pre-marital fertility and cohabitation decisions is based on an empirical model in which we combine time-series variation in county-level economic variables and cross-sectional variation in measures of individual earnings.

Let us assume that we have a group of women who are not married or cohabiting with their partner and are still childless. ${ }^{12}$ An individual's indirect utility function can be represented by $U(B ; X, Y)$, where $B=1$ when the woman has a child and $B=0$ otherwise, $X$ is a vector of individual and family characteristics which could affect the decision to have a child before entering a cohabiting relationship, and $Y$ is a vector of economic variables which reflect labour market opportunities, intended as both employment and earnings opportunities.

A pre-marital birth will occur if and only if:

$$
B^{*} \equiv U^{1}(1 ; X, Y)-U^{0}(0 ; X, Y) \geq 0 .
$$

While we do not observe the utility of the individual, we observe her decision, that is we know that:

$$
B=1 \text { if } B^{*} \geqslant 0 ; \text { and } B=0 \text { if } B^{*}<0 .
$$

Equation (1) should be most appropriately specified in terms of probabilities, but we can adopt a linear approximation and write:

$$
B_{i c t}^{*} \approx X_{i c} \alpha_{0}+Y_{i c t} \alpha_{1}+\eta_{t}+u_{i c t},
$$

where subscript $i$ is for the individual, $c$ for the county, $t$ for time and the term $\eta_{t}$ is simply a fixed period effect.

Even if we assume that the vector $X_{i c}$ is entirely time-invariant and reflects characteristics of the individual and her family which are exogenous to her fertility decision at time $t$, the parameters of equation (3) cannot be consistently estimated if $Y_{i c t}$ is not orthogonal to the error term $u_{i c t}$.

Suppose, however, that we can decompose the vector representing labour market opportunities into two main parts, a vector of county-specific time-variant regressors and an individual-specific time-invariant component, such as the individual permanent or potential wage rate, and that the remaining effects are absorbed by the fixed period effects and by the error term. We can then rewrite equation (3) as follows:

$$
B_{i c t}^{*} \approx X_{i c} \beta_{0}+M_{c t} \beta_{1}+\beta_{2} \ln w_{i c}+\lambda_{t}+u_{i c t}^{\prime} .
$$

Even if we could assume that the vector of local-area economic variables $M_{c t}$ is entirely exogenous, the individual permanent wage rate is likely to be endogenous. In order to take this into account, we specify $\ln w_{i c}$ as:

$$
\ln w_{i c}=X_{i c} \pi_{0}+\phi_{c}+v_{i c},
$$

\footnotetext{
${ }^{12}$ Since our empirical model is a model where pre-marital fertility and cohabitation decisions are considered independent events, we will refer here mainly to pre-marital fertility without loss of generality.
} 
that is, we assume that permanent wages are affected by the entire set of individual and family-specific characteristics and a set of county-specific time-invariant effects, which are supposed to capture the local-area labour market conditions prevailing in the long term (productivity differentials, industry composition, and so on).

It is now possible to write down and estimate the reduced form model:

$$
B_{i c t}^{*} \approx X_{i c} \gamma_{0}+M_{c t} \beta_{1}+\phi_{c}+\lambda_{t}+u_{i c t}^{\prime \prime} .
$$

Additionally, if we assume that county-level fixed effects directly affect individual permanent wages but do not directly determine pre-marital fertility once county-level time-varying economic variables and individual-specific time-invariant difference in wage rates are taken into account, we can obtain consistent estimates of the parameters in equation (4). That is, using county fixed effects as an identifying restriction, we can study the direct impact of individual earnings opportunities on pre-marital fertility.

This identification strategy would be undermined if there were unobserved county-level variables that affect fertility decisions directly rather than through wages or other economic variables. For example, it could be argued that the availability of family planning programmes has a direct impact on pre-marital fertility as it affects people's knowledge about contraceptive methods and costs. Unfortunately, to the best of our knowledge, it is not possible to obtain adequate measures of the availability of family planning services across counties for the period considered. The only information we have that can be disaggregated at the county level is given by the number of visits to family planning clinics for the period between 1993/94 to 2002/2003 in England. Since this is an indicator of both supply and demand of family planning services, it is likely to be endogenous in our model and is therefore not included here.

However, the available empirical evidence shows that the supply of family planning services is not a significant determinant of conceptions or abortion rates for teenage women in England. Instead, it is usually found that other variables, such as economic indexes of deprivation and the level of educational qualification of the population in a certain area, are much more important predictors of the rate of underage pregnancies (see Paton, 2002, and Diamond and et al., 1999). Therefore, even if more research on this issue is certainly needed and some of our results should be interpreted with care, we think that we are controlling for all the most important sources of variation at the county level which may affect pre-marital fertility and cohabitation decisions. ${ }^{13}$

In order to study the determinants of pre-marital fertility, we use an independent competing risk hazard model. The hazard approach is particularly appropriate when the process of interest is a function of the age of the respondent and therefore is clearly suited to our problem because the population at risk can be represented by a sample of single and childless women whose fertility and partnership decisions are observed from age 17 to age 30. Moreover, the model allows us to consider competing risks, i.e. it makes it possible to distinguish exits from the state of single and childless due to pregnancy from those due to entry into a cohabiting relationship. This enables us to analyse separately the determinants of pre-marital fertility and cohabitation.

\footnotetext{
${ }^{13}$ Other variables which could have a direct impact on pre-marital fertility are the ethnic composition of the population resident in the area, or its distribution according to religious faith. In order to control for this, we used the composition of the resident population by counties and ethnicity as recorded by the 1991 Census for Great Britain. This variable, which is time invariant, was found to have no significant effect either on pre-marital fertility or cohabitation even when we did not control for time-varying county-level economic variables. Unfortunately, the 1991 Census did not collect information about religion.
} 
Assume that the distribution of durations in the state of single and childless can be specified by the cumulative distribution function $F(t)=\operatorname{Pr}(T<t)$, which gives the probability that a continuous random variable $T$ is less than some value $t$, and by the corresponding density function $f(t)=d F(t) / d t$. The probability that the duration is longer than $t$ is denoted by the survival function $S(t)=1-F(t)$. The hazard function $\theta(t)=f(t) / S(t)$ can be seen as the probability of completing the duration in the short interval of length $d t$ after $t$, conditional on duration in the state still being uncompleted at time $t$.

Suppose that women who are not in a cohabiting relationship up to nine months before the birth of their first child exit into the 'first child' state. In all other cases we observe either an exit into a 'first cohabiting relationship' or a censored duration. Denote with $j=1,2, \ldots, J$ the different exits and with $\theta_{i j}(t)$ the exit-specific hazard for individual $i$. If we constrain each subject to have a unique failure type, the overall hazard function for individual $i$ is given by:

$$
\theta_{i}(t)=\sum_{j=1}^{J} \theta_{i j}(t)
$$

and the corresponding survival function is:

$$
S_{i}(t)=\exp \left[-\int_{0}^{t_{i}} \sum_{j=1}^{J} \theta_{i j}(u) d u\right] .
$$

Define an exit-specific indicator variable $c_{i j}$, such that $c_{i j}=1$ if individual $i$ exits into state $j$ and $c_{i j}=0$ otherwise, the contribution to the $\log$-likelihood for individual $i$ is:

$$
\begin{aligned}
\ln L_{i} & =\sum_{j=1}^{J} c_{i j} \ln \theta_{i j}\left(t_{i}\right)-\int_{0}^{t_{i}} \sum_{j=1}^{J} \theta_{i j}(u) d u= \\
& =\sum_{j=1}^{J}\left\{c_{i j} \ln \theta_{i j}\left(t_{i}\right)-\int_{0}^{t_{i}} \theta_{i j}(u) d u\right\} .
\end{aligned}
$$

Thus, as shown in Narendranathan and Stewart (1991), independent competing risks models can be easily estimated by partitioning the log-likelihood into a sum of terms, each of which is a function of the parameters of a single exit-specific hazard only. This implies that the parameters of a given exit-specific hazard can be estimated as we would do in a single risk model where durations ending for reasons other than the one considered are treated as censored at the time of completion.

Much of the empirical work on competing risks hazards is set within an independent risks framework. This is because strong identification assumptions are usually required in order to model dependency across the exit-specific hazard functions. ${ }^{14}$ In the absence of valid exclusion restrictions, identifiability is usually achieved through distributional assumptions affecting the treatment of an unobserved heterogeneity component. ${ }^{15} \mathrm{Un}$ fortunately, this approach leads to potentially severe shortcomings, especially when the number of competing risks and the parametric form of the exit-specific hazards are not

\footnotetext{
${ }^{14}$ See Heckman and Honoré (1989), Han and Hausman (1990) and Narendranathan and Stewart (1993).

${ }^{15}$ A recent example is in Brien et al. (1999).
} 
known. This is because the procedure requires the joint estimation of the parameters of all the exit-specific hazards, so that assumptions about the different exits affect the parameters of the hazard of interest (Narendranathan and Stewart, 1993).

In what follows, we estimate a competing risks hazard model where the mutually exclusive exits are represented by a pre-marital conception and a first cohabiting relationship, whereby we do not distinguish between formal and informal unions. For the reasons explained in section 1, we believe that it is very difficult to understand as yet what are the differences between cohabitation and marriage and this means that the choice of the number and types of exits is somewhat arbitrary. This is the main reason why we decided to carry out our analysis within an independent competing risks framework. As the next section shows, we estimate our parameters using both continuous and discrete-time hazard models and with and without controls for gamma-distributed unobserved heterogeneity, always assuming that the unobserved error components are independent across exit-specific hazards. All our estimates are based on a proportional hazard model, where the baseline hazard and the vector of covariates interact multiplicatively.

\section{The results}

\subsection{Pre-marital fertility}

In this section we present the results of our study on the determinants of pre-marital fertility. The sociological literature shows that personal characteristics and circumstances experienced during childhood are associated with a woman's fertility and relationship history. Using information collected in the BCS70, we are able to control for various sources of individual and family background heterogeneity across subjects.

In the first column of Table 2 we show the effect of these variables on a woman's risk of conceiving a child before the beginning of marriage and/or a cohabiting relationship. Column two then shows the impact of time-varying measures of local labour market opportunities without controlling for county fixed-effects. These are included in column three, which thus represent our reduced form equation (6). The last column includes a predicted measure of individual potential earnings, as obtained from the model presented in Table 3, and excludes county dummies.

All the coefficients shown are obtained from the estimation of a proportional hazard model in which duration in the state of single and childless is measured in months since age 17, and the hazard of interest represents exits into pre-marital fertility. The model is estimated using the Cox partial likelihood method. ${ }^{16}$ All the individual or familyspecific variables are dated age 16 or before and the county-level time-varying covariates are always lagged one year with respect to duration in the state.

As we saw in the descriptive analysis, traditional indicators of human capital (such as schooling and measures of ability) appear to be very important determinants of premarital fertility. In particular, column one shows that leaving full-time education at age 16 increases the risk of a pre-marital birth by 2.3 times, whereas a one standard deviation increase in the ability score decreases the likelihood of the event by about $20 \% .{ }^{17}$

\footnotetext{
${ }^{16}$ See Cox (1972).

${ }^{17}$ In the table we report coefficients, but the hazard ratio can be easily calculated by calculating their exponentiated value.
} 
An aspect sometimes emphasized by the sociological literature is the behaviour during childhood, here represented by the first principal component derived from 53 questions about the subject asked to her class teacher. High values of this variable indicate that the child exhibited difficult behaviour, for example she was restless or unable to concentrate on even simple tasks. As we can see, this is only a marginally significant predictor of premarital fertility, and its effect is rather small (about $7.4 \%$ increased risk for one standard deviation increase in the score) compared to what we see for other covariates, suggesting that antisocial behaviour at school cannot be considered one of the most important determinants of pre-marital fertility. ${ }^{18}$

The age of the mother of the cohort member at the birth of her own first child and her marital status are found to be very important predictors of future outcomes throughout the analysis. Both these variables may reflect the influence of cultural and behavioural models of motherhood transmitted within the family and have been emphasized by the sociological literature. In particular, we see that the age of the mother at the birth of her first child is one of the most important variables in this study and is found to significantly and negatively affect the risk of pre-marital fertility. We also see that if the subject's mother had herself been a single mother, a woman would have almost twice the risk of experiencing a pre-marital conception. ${ }^{19}$

Column one also shows that the effect of family income is not significant once we control for tenure of accommodation. As we can see, living in a council house at age 10, as compared to living in a property owned by one's parents, increases the risk of premarital fertility by about $52 \%$. It is possible that the variable 'tenure at age 10 ' reflects not just income but also other important features associated with pre-marital fertility, such as neighbourhood effects, and this would explain its dominating effect over income. Family composition is not significant, except for the number of siblings, which is found to be positively associated with fertility outside a cohabiting relationship. ${ }^{20}$

We also introduce here the social class of the father and that of the mother of the subject. We find generally weak effects of the father's social class, but strong effects of the mother's socio-economic status. The latter variable shows that women whose mothers were in semi-skilled or unskilled manual jobs or who were unemployed or out of the labour force have a significantly higher probability of experiencing a pre-marital birth than women whose mothers worked in professional occupations.

In column two we add controls for county-specific economic factors, which are also time-variant. ${ }^{21}$ We see that the estimated coefficients and the standard errors of the individual and family-specific effects remain almost the same. Of all the county-level variables, the only significant effect is given by the positive impact of county male unemployment rates on the probability of experiencing a pre-partnership conception. The other county-level variables do not have a significant impact on the hazard, and this might be because they generally exhibit much less variation. All the other economic aggregates, such as the male/female wage ratio or the composition of working women by level of skills

\footnotetext{
${ }^{18}$ Both the ability score and the behavioural score variables are treated as continuous variables in this model. Missing values are treated as zeros and indicated by a separate dummy.

${ }^{19}$ See, for example, Berrington and Diamond (2000).

${ }^{20}$ See also Rosenzweig (1999) for a similar finding.

${ }^{21}$ Since we have information about county of residence only at age 10 , all the county specific variables are likely to be affected by a measurement error problem which should induce a downward bias in the estimated coefficients.
} 
are found not to be significant in our model. ${ }^{22}$

It is useful to see what happens when we add county-level fixed effects to the previous specification. As we can see from the third column in Table 2, county fixed effects have a strong impact on the coefficient of unemployment rates, which almost doubles, and on its standard error, which increases more than three times, but the estimated impact of local area unemployment rates on premarital fertility remains significant at the $1 \%$ level and retains its sign (see Moffitt, 1994, for a different result on a similar specification). All the other results remain unchanged and a test of the significance of the county dummies reveals that these are jointly significant only at the $10 \%$ level. Since in the absence of county-level variables the county-dummies are significant at the $1 \%$ level, this reveals that the vast majority of the local-area effects are captured by time and spacial variations in local male unemployment rates. ${ }^{23}$

The reduced form model in column three is then compared to a specification in which we introduce our measure of earnings opportunities and omit county-dummies. Log hourly female wage rates for both working and not working women at age 30 are predicted using the Heckman selection model presented in Table 3, using as our set of independent variables all individual and family specific regressors considered so far. ${ }^{24}$ The latter are taken at age 16, so that this equation predicts the woman's future wage using all the information available at the beginning of the observation period. In the selection model we use as our main identification assumption an exclusion restriction on the mother's interest in the child's education at age 10. This variable is found to be a significant predictor of the woman's employment status at age 30 and we assume that it affects wages only through participation decisions. ${ }^{25}$

The identification of earnings opportunities on pre-marital fertility is based on an exclusion restriction on county dummies in the hazard model. A test of the effect of county-dummies in the wage equation (Table 3) shows that these are jointly significant at the $1 \%$ level, while a likelihood-ratio test of the reduced form (column three) against the restricted hazard model (column four) in Table 2 does not reject the hypothesis that the effect of the county dummies on pre-marital fertility can be captured by predicted earnings. ${ }^{26}$

As shown in the last column of Table 2, where standard errors have been obtained through bootstrapping in order to take into account the two-stage estimating procedure, the effect of earnings opportunities on pre-marital fertility is negative and significant at the conventional level. ${ }^{27}$ In particular, an increase of one standard deviation in hourly wages reduces the likelihood of a pre-marital birth by about $32 \%{ }^{28}$ This is what we

\footnotetext{
${ }^{22}$ Note that we are assuming here that the disturbances in the regression are not correlated within counties although Moulton (1990) shows that in ordinary least squares regressions this could lead to standard errors being seriously biased downwards. Adjusting the standard errors with the cluster option in Stata in order to allow for correlation of observations within counties lead to an increase of the standard errors on the county-unemployment rate coefficient shown in column 2 of Table 2 of less than $2.8 \%$.

${ }^{23}$ Results not shown here, but available on request.

${ }^{24}$ See Heckman (1979).

${ }^{25}$ We controlled for the effect of this variable in our hazard model and we did not find a significant effect on pre-marital fertility or cohabitation decisions.

${ }^{26}$ We obtain a p-value of 0.2067 for a chi-squared test statistics of 63.30 with 55 degrees of freedom. The chi-squared with 55 degrees of freedom has critical values: 82.29 for $1 \%$ significance level, 73.31 for $5 \%$ significance level and 68.79 for $10 \%$ significance level.

${ }^{27}$ The bootstrapping was performed on the first and the second stage equations using 200 replications.

${ }^{28}$ The predicted log hourly wage rate has a mean of 1.9928 and a standard deviation of 0.2058 .
} 
would expect considering that better earnings opportunities increase the opportunitycost of having a child and thus reduce fertility. As we will see in Table 5, we find that earnings have a negative effect on cohabitation, but that this effect is not significant.

The introduction of the earnings variable is also important because it allows us to see whether the individual and family background variables have a direct effect on a woman's fertility and partnership history, for example influencing her preferences and attitudes, or act mainly through the woman's potential wage. As we can see comparing columns three and four in Table 2, variables such as ability, tenure of accommodation, and social class of the mother at age 10 are not significant once we account for the effect of earnings. It thus seems that these variables directly affect future wages, as we can see in Table 3 , but do not have a direct impact on pre-marital fertility. By contrast, other important regressors, such as the age of the mother of the subject at the birth of her first child and the number of brothers and sisters appear to have mainly a direct effect on pre-marital fertility. The coefficient on the schooling indicator becomes much smaller once we control for individual potential wages, but it remains significant at the $1 \%$ level.

Overall this table shows a very clear picture. Women with lower schooling and ability and who come from families with lower labour market opportunities are considerably more likely to become single mothers. Some of these effects act independently of labour market opportunities, but others seem to affect pre-marital fertility only insofar as they affect the subject's future earning potential. Moreover, in all the specifications adopted, county male unemployment rates appear to exert a significant positive effect on the probability of experiencing a pre-partnership pregnancy.

Finally, in Table 4, we look at the role of unobserved heterogeneity which is modeled by means of a discrete time model. This also allows us to obtain an estimate of the baseline hazard, which is specified non-parametrically by using a dummy variable for every six months, and which will be used in order to obtain simulations of the overall effect of unemployment rates as we will see in Table $7 .{ }^{29}$ As we can see from Table 4, the differences between the model with and without unobserved heterogeneity are negligible. The estimated coefficient and the standard errors shown in columns one and two are virtually identical since the estimated variance of the gamma distribution is not significant. This implies that the bias in the parameters due to the effect of unobserved heterogeneity is very small as one would perhaps expect given that the 'first child' hazard shown in Figure 1 exhibits almost no duration dependence.

\subsection{Cohabitation}

In this section we analyse the effect of the regressors considered above on the risk of entering a cohabiting relationship. We do not distinguish between formal and informal unions because such a distinction would imply that these two forms of partnership are alternatives while, in fact, recent studies suggest that in Britain most couples who marry lived together beforehand. Indeed, for a vast majority of people cohabitation may be complementary to marriage, in the same way as a long engagement before marriage may have been necessary in the past. Furthermore, the definition of cohabitation is not as clear-cut as the definition of marriage and many couples have difficulties in reporting

\footnotetext{
${ }^{29}$ Given the computational demands imposed by the estimation of a model with unobserved heterogeneity, the standard errors in Table 4 have not been bootstrapped. However, bootstrapping did not cause major changes in the standard errors of the estimated coefficients (results available on request).
} 
the beginning or the end of a cohabitation spell (Murphy, 2000). It is therefore unclear whether we can distinguish cohabitation from marriage, both because we are still not certain about the nature of the phenomenon and because there is an important issue of data accuracy.

The presentation of the results follows the same outline of the previous section. First, we look at a simple model with individual and family specific variables, then we consider the effect of county-level economic variables and indicators of individual earning opportunities. Table 5 is the main table of interest; it presents the results of the reduced form and structural specification of the model. The wage equation from which our measure of potential earnings is derived is the one presented in Table 3 above. Table 6 shows the effect of controlling for gamma distributed unobserved heterogeneity.

Around $76.4 \%$ of the subjects in our sample leave the state of single and childless to enter a cohabiting relationship. As compared to the previous analysis, in this case we are looking at a much more heterogeneous group of people: some have probably arranged their wedding already and have simply moved in together a few months earlier, others are living with their partner because it is more convenient but have no long-term plans, and there will be couples strongly opposed to the institution of marriage. This implies that, although variation in the timing of the event matters and helps identifying the determinants of cohabitation, it is more difficult to associate this event with specific variables and we expect the effect and the significance of the independent regressors to be less clear than that observed for pre-marital fertility.

Indeed, the picture which emerges from Table 5 to 6 is rather mixed. Some variables have the same effect on the hazard of cohabitation as on pre-marital fertility. In particular, this refers to schooling and the age of the mother of the subject at the birth of her first child. As the latter may also reflect factors associated to the level of educational qualification of the subject, it is possible to think that education exerts a negative effect on both fertility and cohabitation decisions.

As we saw in our results on the 'first child' hazard (Table 2), the marital status of the mother of the subject at the birth of her first child has a significant effect on the 'first child' hazard as it shows that single motherhood is more likely to occur among women whose mother experienced a pre-marital birth. When looking at exits into a 'first cohabiting relationship', however, the mother's marital status matters only insofar as it shows that women whose mother was divorced or separated at the time of the birth of the first child are more likely to enter a cohabiting relationship. However, this effect is not robust to different specifications of the model and we can see in Table 1 that the percentage of women whose mother was separated or divorced at the time of the birth of the first child is very small, so that no strong inference should be drawn with respect to this effect.

Other variables, such as the behavioural test scores and tenure of accommodation at age 10, are not significant at all in the 'first cohabiting relationship' hazard, while we saw that they were generally significant in the 'first child' hazard. Also quite different is the effect of the parents' social class, as in Table 5 we see that the social class of the father is what seems to matter most.

Variables such as ability test scores, and county unemployment rates have the opposite effect on cohabitation decisions with respect to what we observe in the alternative hazard. In this case we are perhaps capturing factors associated with the partner's characteristics and labour market opportunities. As suggested by Rosenzweig (1999), a woman's 
ability test score may capture not only her own but also her partner's earnings potential. Similarly, the county unemployment rate is an indicator of the 'tightness of the marriage market' with a higher level of unemployment restricting a woman's partnership choices or delaying a couple's cohabitation decisions.

Apart from the interpretation of these effects, we see from Table 5 that county-level unemployment rates are always significantly and negatively related to the probability of a transition into a co-residential relationship. In particular, we see that a one standard deviation increase in the local unemployment rate decreases the probability of entering cohabitation by about $12 \%$ when county fixed effects are not included in the model and by about $20 \%$ when they are. In both cases the effect of this variable is significant at the $1 \%$ level. As for our measure of predicted individual earnings opportunities, the last column of Table 5 shows that although the point estimate is negative, the standard error is too large for this effect to have any statistical significance.

Table 6 shows the results of the estimation of a disrete-time model. It is clear that the coefficients are affected by a substantial degree of attenuation bias as after controlling for gamma-distributed unobserved heterogeneity they double in magnitude. This has implications for the quantification of the results, but does not alter the main qualitative aspects of the analysis which still shows a significant and negative impact of county level unemployment rates and a negative, albeit insignificant, effect of individual potential wages on cohabitation decisions.

Overall these results show that poorer local employment opportunities contribute to out-of-wedlock fertility not only by increasing the number of pre-marital births but also by decreasing the probability of entering marriage or cohabitation. The combined direct and indirect effect of this variable on pre-marital fertility is shown in Table 7, where we simulate the effect of a one standard deviation increase in unemployment rate on the percentage of failures into pre-marital births.

Here we can appreciate the size of the total effect of unemployment on pre-marital fertility. This appears to be non negligible even if we take, as a conservative estimate, the coefficients of the model estimated in Tables 4 and 6 without accounting for unobservable heterogeneity. As we can see from our simulation, a deterioration of local area employment opportunities measured by a one standard deviation increase in county-level male unemployment rates would be responsible for an increase in the cumulative percentage of exits into pre-marital fertility of almost $7 \%$ by age 20 . Although this difference becomes smaller over time, so that for example the number of exits which occur due to a pre-marital birth by age 24 is only $4 \%$ higher when unemployment is higher, it is still significant even at the end of the observation period (above $3 \%$ by age 30 ).

\section{Conclusion}

In this paper we use monthly observations on the relationships and fertility histories of a sample of women from the $19^{7} 70$ British Cohort Study to estimate an independent competing risks hazard model of fertility and partnership decisions of women aged 17 to 30 . We are mainly interested in the influence of labour market opportunities, as represented by individual measures of future earnings and county-level indicators of unemployment rates. The effect of the former is estimated by means of a two-step strategy. First, we use all the information available to the individual at age 16 to predict her wage at age 30, and then consider the effect of this measure of potential earnings on fertility and cohabitation 
decisions. Individual earnings opportunities are found to be one of the most important factors affecting conceptions prior to a first partnership. This variable mainly captures the opportunity-cost effect of women's wages and the analysis shows that it is significantly and negatively related to pre-marital fertility and negatively but not significantly related to women's cohabitation decisions.

Consistently with previous findings (Olsen and Farkas, 1990 and Ermisch, 2002) we find that county-level male unemployment rates are positively and significantly related to the risk of a conception occurring before a co-residential relationship even when we control for county-level unobserved effects. Our results also show that poorer local employment opportunities contribute to out-of-wedlock fertility not only by increasing the number of pre-marital births but also by decreasing the probability of entering marriage or cohabitation so that there is evidence of a direct effect of male joblessness on union formation. This latter finding is in contrast with recent empirical evidence for the UK (Ermisch 2002) and is considered evidence in favour of the Wilson hypothesis.

More generally, our study confirms previous research in this area and indicates that economic factors are amongst the most significant determinants of out-of-wedlock births. This is important from a policy point of view, as it suggests that pre-marital fertility reflects optimizing behaviour in the face of economic constraints rather than just the occurrence of 'accidents' due contraceptive failure. It follows that policies focused on improving future job and earnings opportunities of young people in deprived areas might be effective in reducing the numbers of pre-marital pregnancies. 


\section{Bibliography}

Becker, G. S. (1960). "An Economic Analysis of Fertility", in Demographic and Economic Change in Developed Countries, Universities-National Bureau of Economic Research Conference Series 11. Princeton, N. J.: Princeton University Press.

Becker, G. S. (1973). "A Theory of Marriage: Part I", Journal of Political Economy, 81(4), pp. 813-846.

Becker, G. S. (1974). "A Theory of Marriage: Part II", Journal of Political Economy, 82(2), part 2, pp. S11-S26.

Berrington, A. and Diamond, I. (2000). "Marriage and Cohabitation: a Competing Risks Analysis of First-Partnership Formation among the 1958 British Cohort", Journal of the Royal Statistical Society, ser. A, 163(2), pp. 127-151.

Brien, M. J., Lillard, L. A. and Waite, L. J. (1999). "Interrelated Family-Building Behaviors: Cohabitation, Marriage, and Nonmarital Conception", Demography, 36(4), pp. 535-551.

Burdett, K. and Ermisch, J. F. (2002). "Single Mothers", Institute for Social and Economic Research Working Paper 30-2002, University of Essex.

Butler, N., Despotidou, S., and Shepherd, P. (1997). 1970 British Cohort Study (BCS70) Ten-year Follow-up (formerly known as the Child Health and Education Study, CHES): a Guide to the BCS 10-Year Data Available at the Economic and Social Research Council Data Archive. London: Social Statistics Research Unit, City University.

Bynner, J., Butler, N., Ferri, E., Shepherd, P. and Smith, K. (2000). "The Design and Conduct of the 1999-2000 Surveys of the National Child Development Study and the 1970 British Cohort Study", Centre for Longitudinal Studies Working Paper 1. London: Institute of Education.

Cox, D. R. (1972). "Regression Models and Life Tables", Journal of the Royal Statistical Society, ser. B, 34(2), pp. 187-220.

Dearden, L. (1998). "Ability, Families, Education and Earnings in Britain", Institute for Fiscal Studies Working Paper 98/14, London.

Despotidou, S. and Shepherd, P. (1998). The 1970 British Cohort Study, Twenty Six Year Follow-Up, Guide to Data Available at the ESRC Data Archive. London: Social Statistic Research Unit, City University.

Diamond, I., Clements, S., Stone, N. and Ingham, R (1999). "Spatial Variation in Teenage Conceptions in the South and West of England. ", Journal of the Royal Statistical Society, ser. A, 162(3), pp. 273-289.

Ellwood, D. T. and Crane, J. (1990). "Family Change among Black Americans: What Do We Know?", Journal of Economic Perspectives, 4(4), pp. 65-84. 
Ermisch, J. F. (2001). "Cohabitation and Childbearing Outside Marriage in Britain", in $\mathrm{Wu}, \mathrm{L}$. and Wolfe, B. (eds.), Out of Wedlock: Causes and Consequences of Nonmarital Fertility. New York: Russell Sage Foundation.

Ermisch, J. F. (2002). "Employment Opportunities and Pre-marital Births in Britain", paper presented at the XVII Conference of the European Society for Population Economics, Bilbao, Spain.

Ermisch, J. F. and Francesconi, M. (2000). "Cohabitation in Great Britain: Not for Long, but Here to Stay", Journal of the Royal Statistical Society, ser. A, 163(2), pp. 153-171.

Gregory, M., Zissimos, B. and Greenhalg, C. (2001). "Jobs for the Skilled: How Technology, Trade, and Domestic Demand Changed the Structure of UK Employment, 1979-1990", Oxford Economic Papers, 53(1), pp. 20-46.

Han, A. and Hausman, J. A. (1990). "Flexible Parametric Estimation of Duration and Competing Risks Models", Journal of Applied Econometrics, 5(1), pp. 1-28.

Heckman, J. J. (1979). "Sample Selection Bias as a Specification Error", Econometrica, 47(1), pp. 153-161.

Heckman, J. J. and Honoré, B. (1989). "The Identifiability of the Competing Risks Model", Biometrika, 76(2), pp. 325-330.

Kiernan, K. (2001). "European Perspectives on Nonmarital Childbearing", in Wu, L. and Wolfe, B. (eds.), Out of Wedlock: Causes and Consequences of Nonmarital Fertility. New York: Russell Sage Foundation.

Kiernan, K., Lewis, J. E. and Land, H. (1998). Lone Motherhood in Twentieth-Century Britain: from Footnote to Front Page. Oxford: Clarendon Press.

Lerman, R. I. (1989). "Employment Opportunities of Young Men and Family Formation", American Economic Review, 79(2), pp. 62-66.

Lewis, J. (2001). The End of Marriage? Individualism and Intimate Relations. Cheltenham: Edward Elgar Publishing.

Moffitt, R. (1994). "Welfare Effects on Female Headship with Area Effects", Journal of Human Resources, 29(2), pp. 621-636.

Moffitt, R. (1998). "The Effect of Welfare on Marriage and Fertility", in Moffitt, R. (ed.), Welfare, the Family, and Reproductive Behavior. Washington D. C.: National Academy Press.

Moulton, B. (1990). "An Illustration of a Pitfall in Estimating the Effects of Aggregate Variables on Micro Unites", Review of Economics and Statistics, 72(2), pp. 334-338.

Murphy, M. (2000). "Editorial: Cohabitation in Britain", Journal of the Royal Statistical Society, ser. A, 163(2), pp. 123-126.

Murray, C. (1984). Losing Ground. New York: Basic Books. 
Narendranathan, W. and Stewart, B. (1991). "Simple Methods for testing for the Proportionality of Cause-Specific Hazards in Competing Risks Models", Oxford Bulletin of Economics and Statistics, 53(3), pp. 331-340.

Narendranathan, W. and Stewart, B. (1993). "Modelling the Probability of Leaving Unemployment: Competing Risks Hazard Models with Flexible Base-Line Hazards", Journal of the Royal Statistical Society, ser. C, Applied Statistics, 42(1), pp. 63-83.

Olsen, R. J. and Farkas, G. (1990). "The Effect of Economic Opportunity and Family Background on Adolescent Cohabitation and Childbearing among Low-Income Blacks", Journal of Labor Economics, 8(3), pp. 341-362.

Paton, D. (2002). "The Economics of Family Planning and Underage Conceptions", Journal of Health Economics, 21(2), pp. 207-225.

Rosenzweig, M. R. (1999). "Welfare, Marital Prospects, and Nonmarital Childbearing", Journal of Political Economy, 107(6), pp. S3-S32.

Upchurch, D. M., Lillard, L. A. and Panis, C. W. A. (2001). "The Impact of Nonmarital Childbearing on Subsequent Marital Formation and Dissolution", in Wu, L. and Wolfe, B. (eds.), Out of Wedlock: Causes and Consequences of Nonmarital Fertility. New York: Russell Sage Foundation.

Willis, R. J. (1999). "A Theory of Out-of-Wedlock Childbearing", Journal of Political Economy, 107(6), pp. S33-S64.

Willis, R. J. (2000). "The Economics of Fatherhood", American Economic Review, 90(2), pp. $378-82$.

Wilson, W. J. (1987). The Truly Disadvantaged: the Inner City, the Underclass, and Public Policy. Chicago: University of Chicago Press.

Wilson, W. J. and Neckerman, K. (1986). "Poverty and Family Structure: The Widening Gap Between Evidence and Public Policy Issues", in Danziger, S. and Weinberg, D. (eds.), Fighting Poverty. Cambridge, Massachusetts: Harvard University Press.

Wood, R. G. (1995). "Marriage Rates and Marriageable Men: a Test of the Wilson Hypothesis", Journal of Human Resources, 30(1), pp. 163-193. 
Figure 1: Smoothed hazard functions

\section{Panel A: First child and first cohabiting relationship}

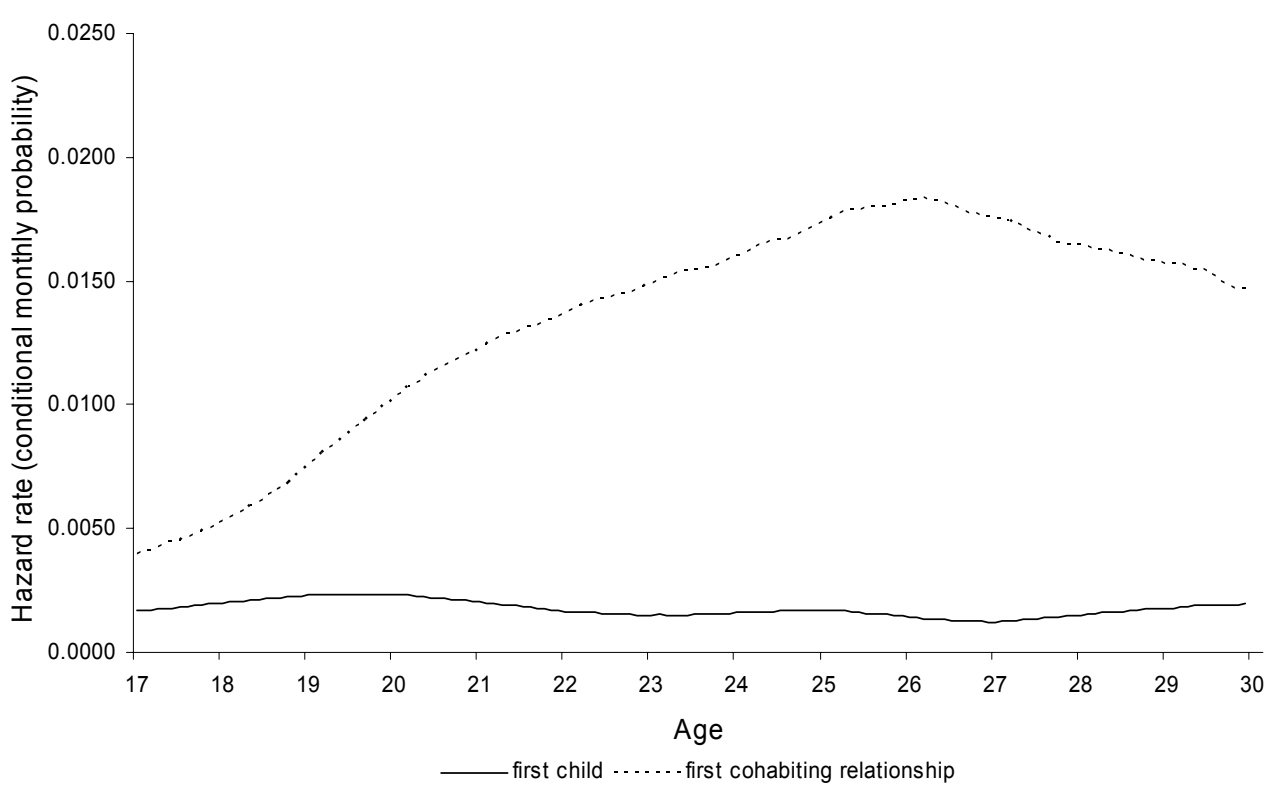

Panel B: First child

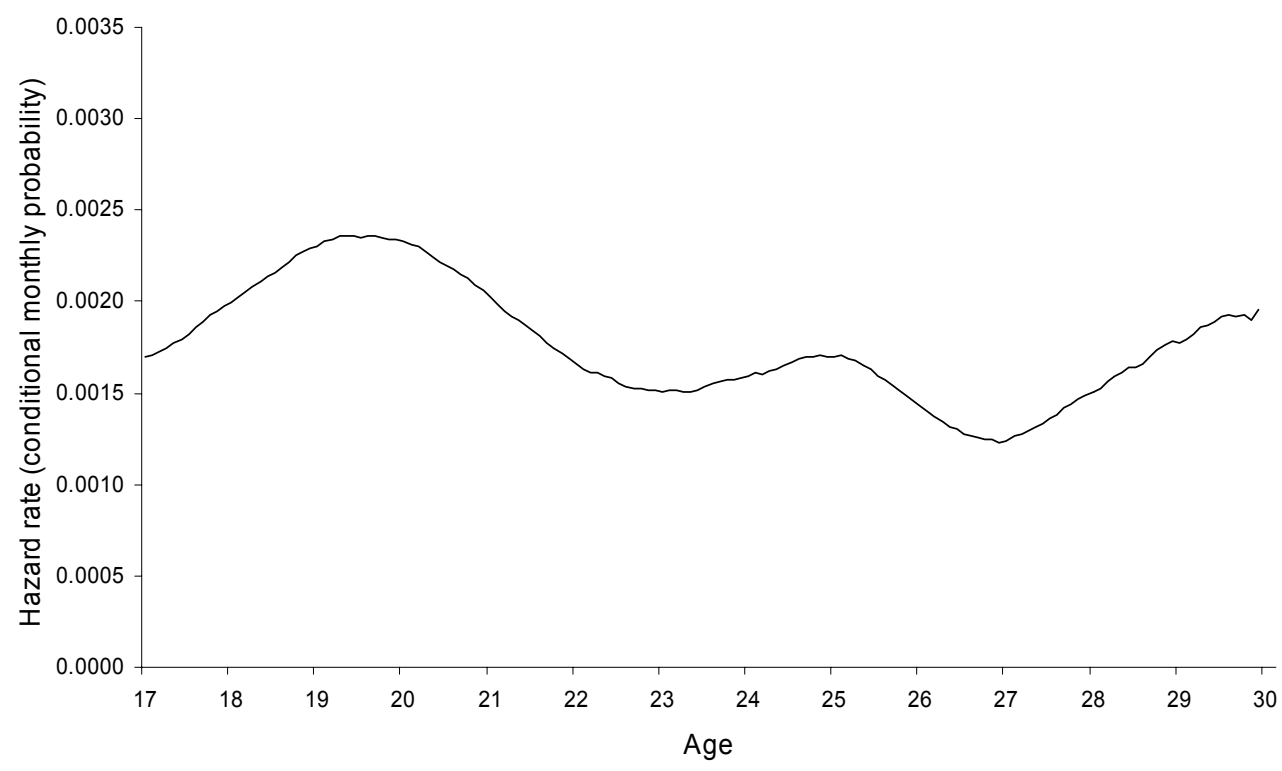




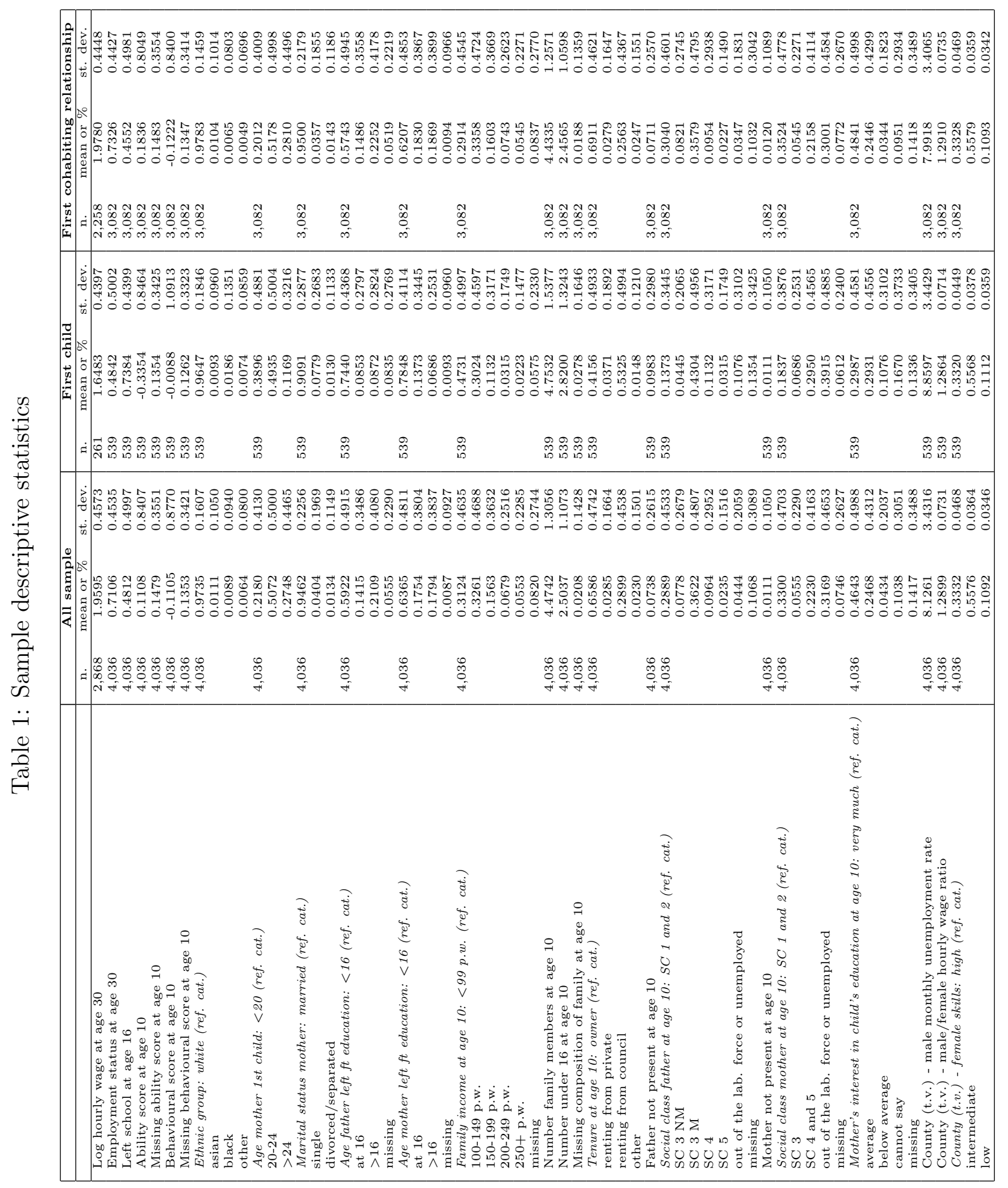




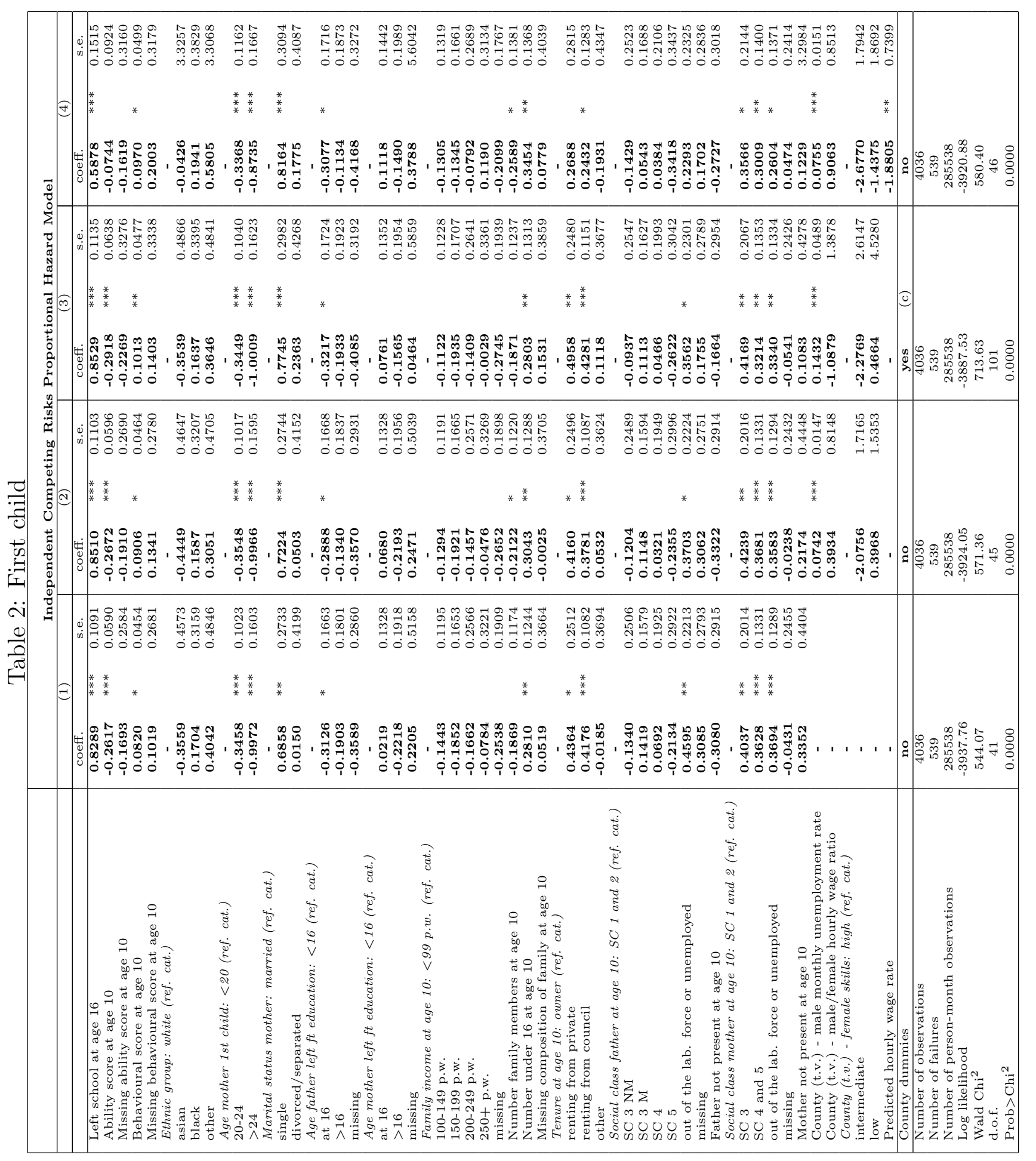

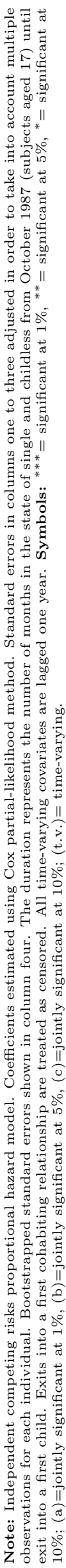




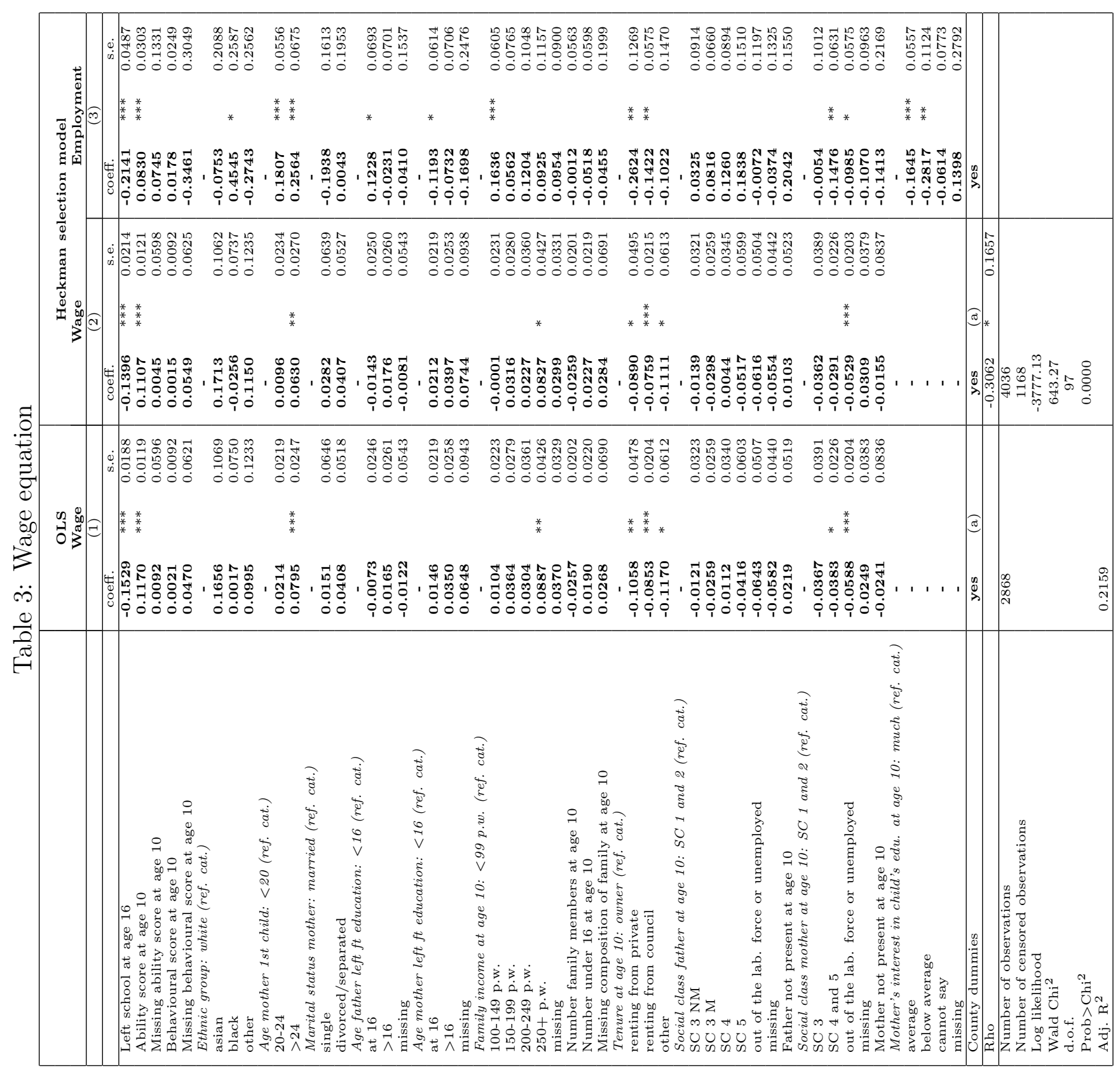

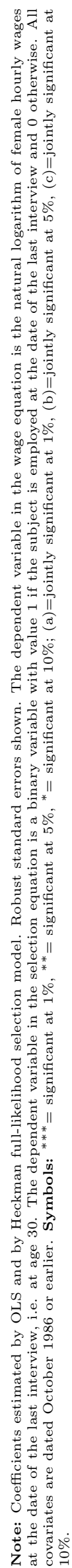




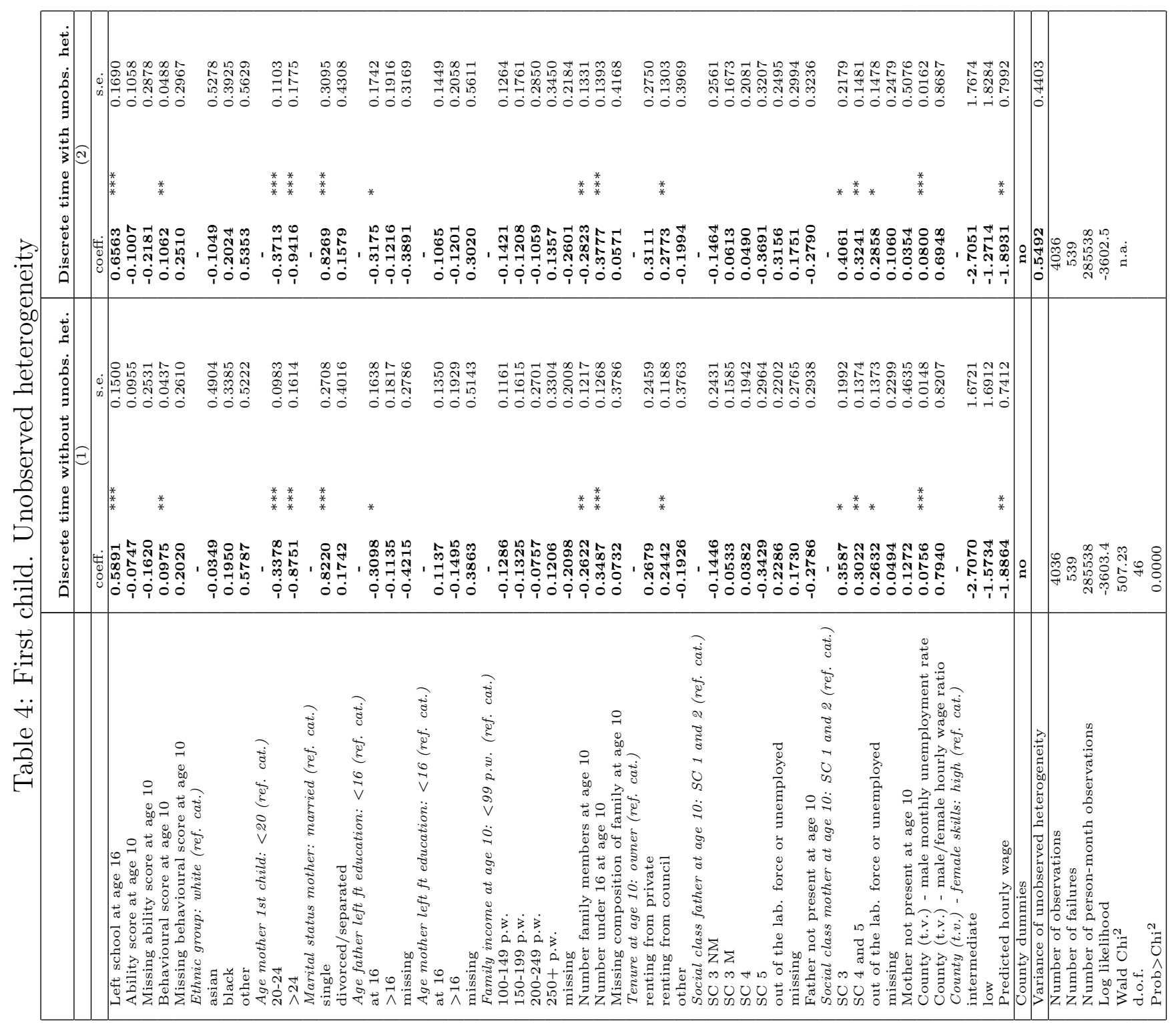

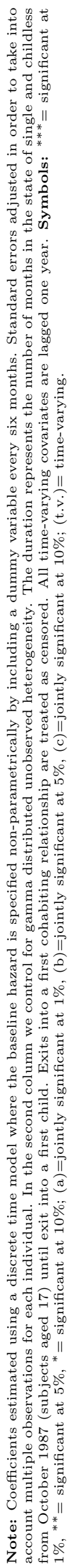




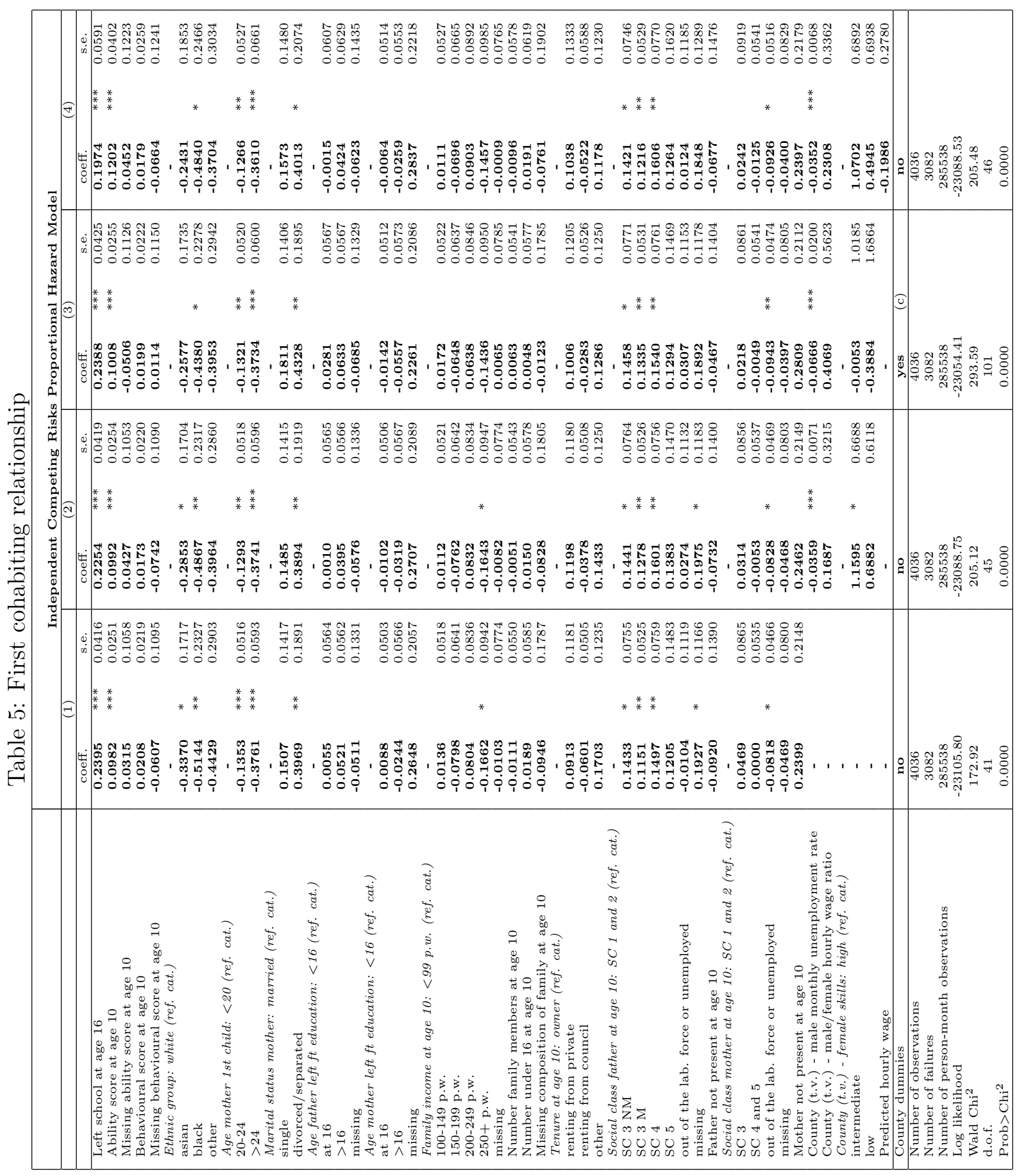



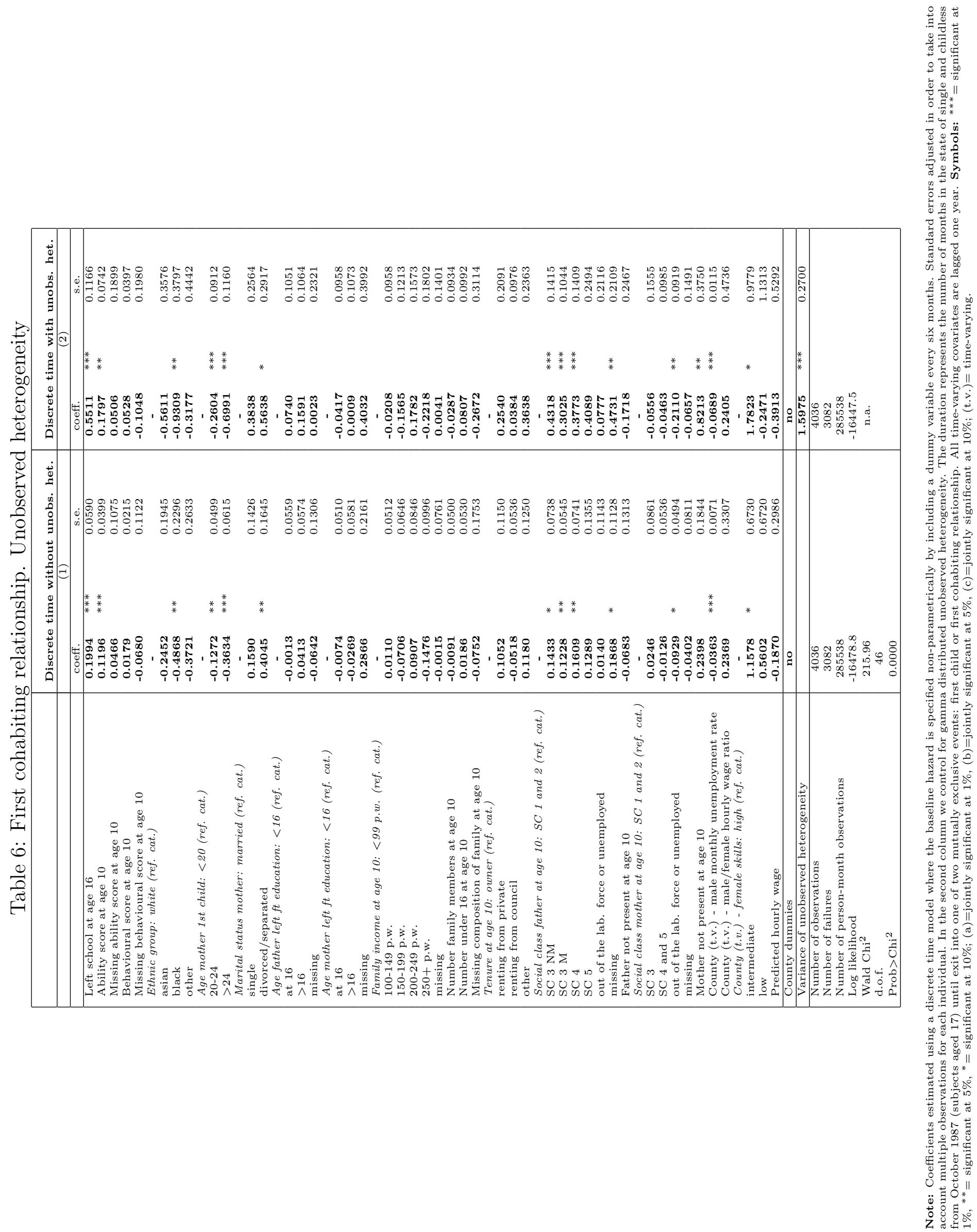


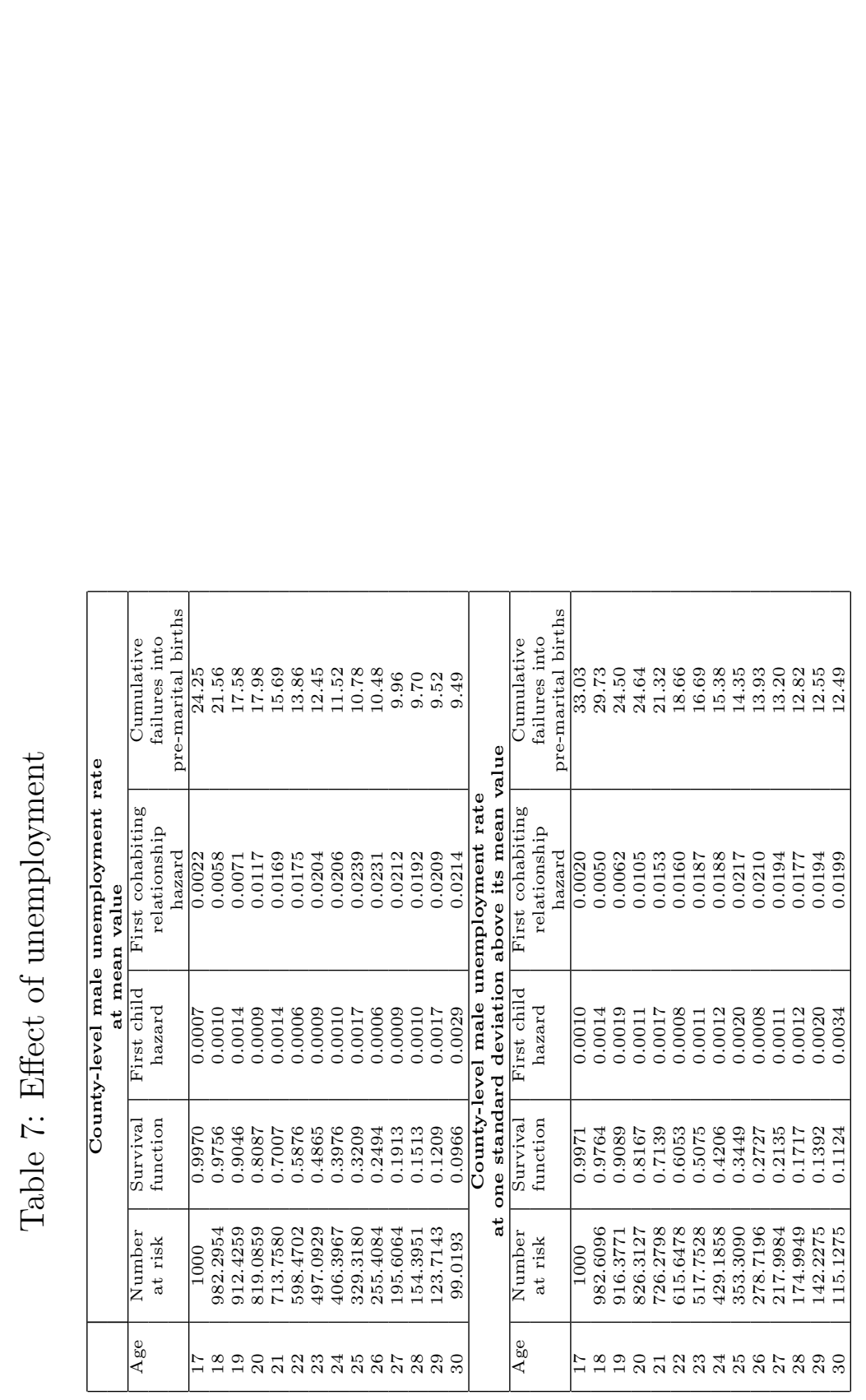

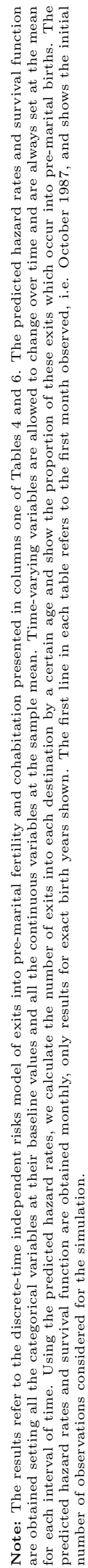

